\title{
FACTORS INFLUENCING PUBLICATION OF SCIENTIFIC ARTICLES DERIVED FROM MASTERS THESES IN PUBLIC HEALTH
}

Hollmann M, Borrell C*, Garin O, Fernández E, Alonso J.

\begin{abstract}
Objective: To evaluate theses of a Masters program in Public Health (MPH), in terms of the students' and theses' characteristics that influence publication of the thesis as a scientific article.
\end{abstract}

Methods: Longitudinal study of students who successfully completed the MPH at Universitat Pompeu Fabra and Universitat Autònoma de Barcelona (Spain) from 2006 to 2010. Participants completed an electronic survey and additional data was gathered from university files.

Results: 162 students participated in the study ( $83 \%$ response rate). $60.5 \%$ had already published an article derived from their thesis at the time of the study or were in process of publishing it. The likelihood of publishing in a peer-reviewed journal was greater among women (aRR=1.41), among those who had a bachelor's degree in sciences other than health (aRR=1.40), had completed the $\mathrm{MPH}$ on time (aRR=2.10), had enrolled in a doctoral program after the MPH (aRR=1.44) or had a masters thesis score of $\geq 7(\mathrm{aRR}=1.61)$.

Conclusion: The majority of MPH students published their thesis in a peer-reviewed journal. The strongest predictors of successful publication were related to academic performance.

Key words: Public health, education, publication, postgraduate students, masters theses 


\section{INTRODUCTION}

Graduate courses such as masters, doctorates, and post-doctorates are the highest level of training offered by education systems. Consequently, excellence is expected in all components of the training program. Programs are directed to increase academic level and professional performance by strengthening social, scientific, political, cultural, and ethical relevance (European Union 1997).

Following the Bologna declaration, Europe has undergone a process of convergence of higher education systems, framed within the European Higher Education Area (European Union 2003).It was agreed that the curricula of Masters degrees should contain all the theoretical and practical training the student requires according to the special characteristics of each area. The culmination of the learning process in a masters degree is the preparation, presentation, and public defense of a masters thesis (Ministerio de Educación y Ciencia. Gobierno de España 2007) which is intended to provide practical training in the scientific method and to develop a scientific attitude in students. Since masters theses are based on a modest research project conducted by the student with the support of a tutor, they are regarded by universities as a potential indicator of the overall quality of the program (Kim, McKenna and Ketefian 2006; Dundar and Lewis 1998).

One of the main pillars of modern higher education systems is research, and as a result, the dissemination of the knowledge generated (European Union 1997; Ministerio de Educación y Ciencia. Gobierno de España 2007). The preferred mode of research dissemination is the publication of findings in peer-reviewed journals. In fact, publication in journals is typically used to assess the quality of research (Salmi, Gana and Mouillet 2001; Bordons and Zulueta 1999); thus, in many academic institutions it is one of the main avenues for pursuing a career in research (Bullen and Reeve 2011; Lowcay et al. 2004). While it is not compulsory for masters students to publish the results of their masters thesis, it is encouraged by most masters programs, given its academic 
and professional benefits, and in accordance with standard research practice and the social responsibility of scientists. Despite this, many young researchers do not succeed in publishing their masters theses (Bullen and Reeve 2011; Tobar and Romano Yalour 2002; Giglio 2009; Dhaliwal, Singh and Bhatia 2010). The scant literature suggests a series of barriers and facilitating factors, including the student's motivation to publish, the support and mentoring received, and other characteristics such as the student's age, type of work, and family burden (Bullen and Reeve 2011; Dhaliwal, Singh and Bhatia 2010). A more comprehensive evaluation of the factors influencing publication of scientific articles derived from masters theses that includes students' academic performance is still lacking. Furthermore, this information can be used by universities to improve the rate of success and quality of publications derived from masters theses.

We assessed the publication of masters theses from the Masters program in Public Health offered by Pompeu Fabra University (UPF) and the Autonomous of Barcelona University (UAB) in Barcelona, Spain. This masters program is officially accredited by the Spanish Education Agency within the European Higher Education Area. The mission of the MPH is to train students to understand the processes of health/disease and its determinants from a population perspective, and to address health problems through collective interventions that promote, protect and restore health. The program places a strong emphasis on research and on the student's performance in writing their thesis.

The objective of this study was to characterize the students and theses of the Masters program in Public Health, and to assess the factors that influence publication of the results of the theses as scientific articles in peer-reviewed journals. 


\section{METHODS}

The Masters in Public Health (MPH) was first organized in Catalonia, Spain, by the Universitat de Barcelona (UB) in 1989. It was offered at this university until 1999, and was subsequently undertaken by the Universitat Pompeu Fabra from 2000 onward. In 2006 the program was given the status of European Official Master, and since then it has been jointly organized by the Universitat Pompeu Fabra (the coordinating institution) and the Universitat Autònoma de Barcelona.

The MPH offers students 4 different specialties: Public Health Research, Community Health, Preventive Medicine, and Environmental Health. Physicians enrolled in the Public Health and Preventive Medicine residency training program have to enroll mandatory the MPH (Preventive Medicine specialty). The duration of the MPH for the editions considered was one academic year (except for the Community Health specialty, which was a two-year program during the first three editions). Each edition of the masters program is referred to by the year in which it began.

In accordance with Spanish law regarding the acquisition of a Master degree, completion of a thesis is compulsory. The master thesis is intended to provide practical knowledge through the development of a research or intervention project with the structure of a scientific article (Universitat Pompeu Fabra and Universitat Autònoma de Barcelona 2012). It can be conducted at one of several research, academic, and public health institutions affiliated with the MPH program. The MPH does not publish students' masters thesis in any format.

\section{Design and Study Sample}

We performed a longitudinal study that included a cross-sectional survey. The study population consisted of students who successfully completed the MPH in one of 5 consecutive editions of the program ( $n=210$ ), from 2006 to 2010. Students who validated a thesis from another degree 
program (either a masters or doctoral degree) were excluded $(n=14)$.Thus, the total number of eligible students was 196.

\section{Ethical Considerations}

This study was approved by the Clinical Ethics Research Committee of Parc de Salut Mar, according to current Spanish law (Law 15/99 on protection of personal data) (Gobierno de España 1999) and the declaration of Helsinki. Only students who agreed to participate in the study were included.

\section{Data Collection and Information Sources}

Students were contacted by e-mail and/or telephone between August 2013 and February 2014 to participate in the study. Those who agreed to participate were asked to complete an electronic questionnaire to gather information about their current activities and residence, their perception of the masters, and information about the publication of their thesis (categorized as: published; not yet published but in process; sent for publication but rejected; and never sent for publication). Information about articles in the process of being published or theses not yet published was updated until March 2014, regardless of the date of response to the survey. Socio-demographic and academic data of the participants were obtained from university files. Information about the publication of the theses was verified for all eligible students using databases on biomedical topics: PubMed/MEDLINE and Scopus, and the bibliometric characteristics of the journals where the articles were published were obtained from the Journal Citation Reports (JCR), Web of Science.

\section{Study Variables}

The principal variable of interest was publication of the results of the thesis, which was subsequently dichotomized into yes (thesis already published or in process) and no (sent to at least one journal but rejected and withdrawn, or never sent). Those students who did not publish 
their thesis were asked about the barrier/s for not publishing it. Other variables of interest in the study were as follows:

Sociodemographic characteristics: age in years at enrollment in the MPH; sex; country of origin, dichotomized into international student (country of origin other than Spain: no/yes); enrollment in the MPH through a scholarship; current work.

Academic data: undergraduate degree; chosen MPH specialty; physician enrolled in Public Health and Preventive Medicine specialty; MPH completed on time; enrolled a doctoral program after MPH.

Masters thesis characteristics: topic area; research methodology (quantitative or qualitative); center where it was carried out; qualification (scores between 5-pass mark, and 10-excellent).

Bibliometric indicators (only for theses already published): journal-related (name, impact factor-IF during the year of publication, 2012 5-year IF, quartile, decile); article-related (language, order of student authorship, time elapsed in months between the completion of the MPH and acceptance of the article for publication in a peer-reviewed journal).

\section{Analysis}

In addition to the descriptive analysis, we performed bivariate analyses using the Chi-square Test (Pearson or Fisher, as required) for qualitative variables, the U Mann Whitney test for quantitative non-normally distributed variables, and T-student test for quantitative normally distributed variables. Relative Risks (RR) and their 95\% confidence intervals (Cl) were obtained for variables that were significantly associated in the bivariate analysis. We also computed adjusted RR (aRR) and $95 \% \mathrm{Cl}$ using multivariate robust Poisson regression to identify factors that determine success 
in publishing the results of theses. Statistical analyses were carried out using SPSS v18 and STATA v11.

\section{RESULTS}

We invited 196 students to participate in the study, of whom 162 (83\%) completed the survey. Response rates ranged from 68\% for the 2006 edition, to $100 \%$ for the 2010 edition. We found no statistically significant differences between editions for any of the variables analyzed. There were also no significant differences $(p>0.05)$ between students who participated and did not participate in terms of sex, age, country of origin, academic characteristics, thesis characteristics, percentage of articles published, and the bibliometric characteristics of the articles and journals, with the exception of the language in which the article was published.

Table 1 describes the characteristics of the 162 participants. Just over $75 \%$ of students were women and the median age at enrollment in the MPH program was 28 years (interquartile range, IQR 26 - 34 years). The geographical background of the participants was very heterogeneous (58\% Spain, $8 \%$ rest of Europe, $32 \%$ America, $2 \%$ rest of the world), as well as their undergraduate studies: $29 \%$ were physicians, $10 \%$ nurses, $28 \%$ had studied other health sciences, $12 \%$ statistics or mathematics, $9 \%$ social science, $7 \%$ biology, and $4 \%$ economic science. In relation to the theses, the vast majority (93\%) were quantitative studies and the most common subject area was research in health services (28\%). The median thesis qualification was 8 in a scale from 0 to 10 (IQR 7 - 9). At the time of the survey, almost two thirds of the students were working in a job related to public health. Most students $(80 \%)$ agreed or strongly agreed with the following statement: "the MPH was an improvement in my professional status and/or progress in my career". 
Ninety-eight students (60.5\%) indicated that they had successfully submitted an article for publication based on their MPH thesis. Of these, 87 had already published the article at the time of the study, and 11 were in the process of publication. Sixty-four students (39.5\%) had not published the results of their thesis, 52 of whom had never submitted it for publication, and 12 had had it rejected and had not submitted it again.

As shown in Table 2, publication of the results of the thesis was significantly associated $(p<0.05)$ with sex, age at the start of the MPH, field of undergraduate training, whether the MPH completed on time, whether the student had enrolled in a doctorate program after the MPH, the thesis topic area, the thesis score, the present job, and whether they agreed that the MPH had improved their professional status and/or career progress.

Table 3 summarizes the results of the analysis of variables that best explain the differences in MPH students' success in publishing the results of their theses. The likelihood of publishing in a peerreviewed journal was greater among women $(a R R=1.41,95 \% \mathrm{Cl} 1.01-1.98)$, and among those who had a bachelor's degree in sciences other than health (aRR=1.40,95\% Cl 1.11-1.74), had completed the $\mathrm{MPH}$ on time $(\mathrm{aRR}=2.10,95 \% \mathrm{Cl} 1.20-3.68)$, had enrolled in a doctoral program after the MPH $(a R R=1.44,95 \% \mathrm{Cl} 1.13-1.84)$, or had a masters thesis score of $\geq 7(a R R=1.61,95 \% \mathrm{Cl} 1.12-2.32)$.

Students who did not publish their thesis $(n=64)$ reported the following barriers they thought that could have negatively affected to publish: work load (29\%); insufficient tutor support (20\%); publication bias for "negative" (non-significant or unfavorable) results (17\%); insufficient motivation/personal interest (12\%), family burden (9\%), and other barriers $(13 \%)$. We found no statistically significant differences in the barriers reported between the students who never submitted their thesis for publication $(n=52)$ and those whose articles were rejected $(n=12)$. 
Figure 1 shows the bibliometric indicators of the published articles and journals $(N=87)$. Articles were published in 58 different journals, the most popular of which were Gaceta Sanitaria (15\%) and PLOS One (5\%).Most students were the first author of the published article (82\%).The median 2012 5-yearIF was 2.62 (IQR 1.25 - 3.85), and the median IF for the year of publication was 2.37 (IQR 1.39 - 3.50). The mean and median time in months between completion of the MPH and acceptance of the article was $19.1(95 \% \mathrm{Cl} 17.1-21.0)$ and 18.8 (IQR $11.8-24.7)$ respectively. 


\section{DISCUSSION}

To our knowledge this is the first study in Europe that has evaluated factors influencing success in publishing the results of theses of MPH students in peer reviewed journals. Sixty one percent of MPH students had published their theses or were in the process of doing so. The percentage of published theses was higher than that reported by the only other MPH study that has assessed this topic as far as we are aware (40\%, New Zealand) (Bullen and Reeve 2011). The reported publication rate of masters theses in other disciplines ranges from $30 \%$ to $44 \%$ ( Dhaliwal $U$ et al. 2010; Arriola-Quiroz I et al. 2010; Salbach N et al. 2013). This study allowed us to identify several factors associated with publication success in this context. Our results highlight similar barriers to publish as previous studies with similar objectives (Bullen and Reeve 2011; Schattner et al. 2007).

\section{Facilitators and Barriers}

Participants were from diverse geographical and academic backgrounds. While geographical background did not appear to influence publication success, field of undergraduate studies did appear to do so. Graduates from health-related fields had lower publication success than nonhealth graduates. This might be due to the multidisciplinary perspective of public health research, which extends well beyond a biomedical perspective (Sian Griffiths, Crown and McEwen 2007; S Griffiths, Jewell and Donnelly 2005; Harris et al. 2011; Jamison et al. 2013).

Workload was the most commonly cited barrier to publication. It is noteworthy that in most cases students need to improve the articles before submission, and it is well known that the publication process is demanding and take-consuming (Chen 2011). The following situations might have occurred: some students were not working, and they could full-time dedicate to the completion of their thesis; others worked in institutions where they developed their research project as part of their job; and yet others had unrelated jobs and could not use their working time for that purpose. 
Unfortunately, these situations were not assessed in our study. Moreover, the employment status of the students during the MPH could be related to their academic performance, assessed by their thesis qualification and their ability to complete the MPH on time, factors strongly associated with publication success.

Only 8 students (9\%) identified family burden as a barrier to publishing their theses, six of whom were women (75\%), which is consistent with the percentage of women in the study. Our findings do not support the fact that women had a greater family burden than men as many other studies have concluded (King-Shier and Singh 2014; Bratberg 2002; Viana et al. 2013; Patton and Johns 2007); at least in this case, women did not identified family burden as a barrier to publishing. On the contrary, women in this study published 1.4 times more than men. While we had hypothesized that the reason from a more likely thesis publication by women students could be related to a better overall program performance, we found no gender differences in mean program performance scores ( 7.76 for women vs. 7.80 for men, $p=0.66$ ) neither in theses qualifications (7.89 for women vs. 7.87 for men, $p=0.90$ ).

While masters theses should not be conducted simply to fulfill a degree requirement, there are some time and other program constraints which limit to some extent the possibility that masters theses produce innovative or significant research findings (Younes, Deheinzelin and Birolini 2005). This clearly influences the likelihood of subsequent publication. In fact, $17 \%$ of the students had identified publication bias against non-significant or unfavorable results as a barrier to publishing.

Our detailed examination of data on institutions and tutors highlighted the importance of these two factors. We observed that some institution-tutor combinations achieve greater thesis publication success than others. The fact that $20 \%$ of students reported insufficient tutor support as a barrier to publishing indicates the importance of appropriate tutor support during the process 
of developing and publishing the thesis. It is also important to account for the fact that the publication process also demands significant time and resources from the tutors. However, publication is an additional merit for tutors, which should encourage them to support the student in getting the thesis published (Nieminen et al. 2007). It should also be noted that health services and public health organizations, whose main mission is not research, have less time to complete the process of publication as a result of their greater public health workload. Our results are consistent with those of Bullen and Reeve (Bullen and Reeve 2011), who assessed this topic in greater detail, and we also consider that these factors need further research.

Publishing success was considerably higher among students who continued their research career as doctoral researchers, independently of the topic of the doctorate, whether in public health, medicine or another field. This result is not surprisingly as these students are more interested in research than the rest. Publishing success and continuation as doctoral researchers may influence each other mutually: the MPH program stimulates the students' capacity and necessary tools for research; in addition, holding a master degree is a mandatory requirement for pursuing a doctorate in Spain and Europe (Ministerio de Eduación Cultura y Deporte. Gobierno de España). Nevertheless, it should be noted that the MPH not only trains researchers but also public health professionals, who might not always been interested in publishing. In fact, $12 \%$ of the student who did not publish their theses cited insufficient motivation or personal interest as a barrier. Moreover, many students moved into a different field soon after the MPH and lost the motivation to publish their theses (Bullen and Reeve 2011).

We observed a positive association between the students' perceived improvement in their career due to the MPH and the likelihood of publishing their theses. This might indicate the importance for the students and the public health field of having scientific articles published (European Union 
1997; Ministerio de Educación y Ciencia. Gobierno de España 2007; Nieminen et al. 2007). Certainly, the publication itself adds value to the student's curriculum. We believe that encouraging masters students to publish their MPH thesis might turn on future academic and professional benefits. However, we do not suggest that publication should be a criterion to achieve a master degree. But completing the mandatory MPH thesis in the format of a publishable article might be advisable.

\section{Article Characteristics}

The articles were published in a heterogeneous range of peer-reviewed journals and subject areas, which reflects the wide range of research in public health. Considering the fact that the publication process is generally quite long (Chen 2011; Dhaliwal, Singh, and Bhatia 2010), the observed one and a half year gap between conclusion of the MPH and acceptance of the article indicates an active process by both students and tutors.

Despite publication rates differences between qualitative and quantitative research theses did not reach statistical significance due to the small number of the former, publication rates for qualitative studies were very low. While there is evidence of an increase in the proportion of qualitative research in medical journals over the last decade, the proportion remains low (Shuval et al. 2011) and qualitative studies are rarely published in high impact journals (Gagliardi and Dobrow 2011). Our results are consistent with other studies that have assessed this topic deeply (Shuval et al. 2011; Gagliardi and Dobrow 2011; Stern and Simes 1997).

First authorship issues might pose a dilemma when research involves a larger study. Furthermore, at the beginning of the thesis the student rarely had the skills or knowledge necessary to conceptualize a study. However, it is noteworthy that the large majority of students were first 
authors and also that articles were published in high-level journals. This represents added value for MPH graduates who successfully published their theses (Bordons and Zulueta 1999).

\section{Limitations and Strengths}

When interpreting the results of our study, some limitations should be considered. First, information about the publication of the theses was updated until March 2014; it could be possible that more theses were published after that date. Second, while our study achieved a high response rate, and therefore good internal validity, our findings are not automatically comparable with those of other programs because only the public health discipline has been analyzed, and also because emphasis on research and publication might vary between masters programs. In particular, this MPH emphasizes the thesis work, which might not be the case in other MPH programs. In spite of the limited scope of our study, our findings maybe valuable for others masters programs, especially in Europe. Although the overall publication rate might differ between MPH programs, we believe that the observed associations may quite accurately represent associations elsewhere, so these results may be transferable to other masters programs. Further studies might assess the strong of these associations in other masters programs allowing the comparison between them.

The main strengths of our study include: first, a very high response rate $(83 \%)$, which also demonstrates the high level of interest in our research shown by the students; second, in order to obtain valid data, we used different sources of information (students' responses to the survey, PubMed, Scopus, university records) and, subsequent cross-verification of these data where appropriate. Finally, information about publication of the thesis' results as well as the bibliometric characteristics of the publishing journal were evaluated for all eligible participants, both 
responding and non-responding students, and no differences were observed between these groups. These strengths support internal validity of the study.

\section{Conclusions}

Most masters theses of our MPH program are disseminated in the scientific literature. The strongest predictors of publishing success are related to academic performance.

Our study provides original information that might help those programs interested in increasing the level of publications derived from masters theses. Also it highlights the importance of providing the students the necessary tools and support to achieve the publication of their theses.

Given the relevance of the debate surrounding the role of postgraduate education in addressing modern health challenges related to human resources in public health (World Health Organization 2006), our study emphasizes the importance of evaluating MPH programs through their scientific productivity among other indicators. 


\section{REFERENCES}

Arriola-Quiroz I, Curioso WH, Cruz-Encarnacion M, Gayoso O (2010) Characteristics and publication patterns of theses from a peruvian medical school. Health Info Libr J 27 (2): 148-54. doi:10.1111/j.1471-1842.2010.00878.x.

Bordons M, Zulueta, MA (1999) Evaluación de la actividad científica a través de indicadores bibliométricos. Rev Esp Cardiol 52:790-800.

Bratberg, E (2002) The double burden: do combinations of career and family obligations increase sickness absence among women? Eur Sociol Rev 18 (2): 233-49. doi:10.1093/esr/18.2.233.

Bullen CR, Reeve J (2011) Turning postgraduate students' research into publications: a survey of New Zealand masters in public health students. Asia Pac J Public Health 23 (5): 801-9. doi:10.1177/1010539511417998.

Chen, X-P (2011) Author ethical dilemmas in the research publication process. Manag Organ Rev 7 (3): 423-32. doi:10.1111/j.1740-8784.2011.00229.x.

Dhaliwal U, Singh N, Bhatia A (2010) Masters theses from a university medical college: publication in indexed scientific journals. Indian J Ophthalmol 58 (2): 101-4. doi:10.4103/03014738.60070 .

Dundar H, Lewis D (1998) Determinants of research productivity in higher education. Res High 39 (6):607-631.

European Union (2003) Bologna process - European Higher Education Area web. (http://www.ehea.info/) Accessed 23 September 2013.

European Union (1997) Convention on the recognition of qualifications concerning higher education in the European region. Accessed 26 September 2013. Available at: http://conventions.coe.int/Treaty/EN/Treaties/Html/165.htm

Gagliardi AR, Dobrow MJ (2011) Paucity of qualitative research in general medical and health services and policy research journals: analysis of publication rates. BMC Health Serv Res 11(1) 268. doi:10.1186/1472-6963-11-268

Giglio, D (2009) Difficult for postgraduate medical students to find time and money for research. Still the degree of publishing and theses is rather high. Läkartidningen 106 (14): 999-1003.

Gobierno de España (1999) Ley Orgánica 15/1999, de 13 de diciembre, de protección de datos de carácter personal. Accessed 12 December 2013. Available at: https://www.boe.es/boe/dias/1999/12/14/pdfs/A43088-43099.pdf.

Griffiths S, Jewell T, Donnelly P (2005) Public health in practice: the three domains of public health. Public Health 119 (10): 907-13. doi:10.1016/j.puhe.2005.01.010. 
Griffiths S, Crown J, McEwen J (2007) The role of the faculty of public health (Medicine) in developing a multidisciplinary public health profession in the UK. Public Health 121 (6): 420-25. doi:10.1016/j.puhe.2007.02.021.

Harris JK, Beatty KE, Lecy JD, Cyr JM, Shapiro RM (2011) Mapping the multidisciplinary field of public health services and systems research. Am J Prev Med 41(1):105-111. doi:10.1016/j.amepre.2011.03.015.

Jamison DT, Summers LH, Alleyne G, Arrow KJ, Berkley S, et al (2013) Global health 2035: a world converging within a generation. Lancet 382(9908):1898-1955. doi:10.1016/S01406736(13)62105-4.

Kim MJ, McKenna HP, Ketefian S (2006) Global quality criteria, standards, and indicators for doctoral programs in nursing; literature review and guideline development. Int J Nurs Stud 43 (4): 477-89. doi:10.1016/j.ijnurstu.2005.07.003.

King-Shier K, Singh S, Leblanc $P$, et al (2014) The influence of ethnicity and gender on navigating an acute coronary syndrome event. Eur J Cardiovasc Nurs. doi:10.1177/1474515114529690

Lowcay B, Mcintyre E, Hale M, Ward MA (2004) Peer reviewed publication rates. Aust Fam Physician 33 (4): 284-86.

Ministerio de Educación y Ciencia. Gobierno de España (2007) Real Decreto 1393/2007, de 29 de octubre, por el que se establece la ordenación de las enseñanzas universitarias oficiales. Accessed 23 September 2013. Available at: http://www.mecd.gob.es/educacionmecd/areas-educacion/universidades/educacion-superior-universitaria/organizacionensenanza-universitaria.html

Nieminen P, Sipilä K, Takkinen H-M, Renko M, Risteli L (2007) Medical theses as part of the scientific training in basic medical and dental education: experiences from Finland. BMC Med Educ 7:51. doi:10.1186/1472-6920-7-51.

Patton E, Johns G (2007) Women's absenteeism in the popular press: evidence for a genderspecific absence Culture. Hum Relations 60 (11): 1579-1612. doi:10.1177/0018726707084301.

Salbach N, O'Brien K, Evans C, Yoshida K (2013) Dissemination of student research in a canadian master of science in physical therapy program. Physiother Canada 65 (2): 3138. doi:10.3138/ptc.2012-18.Dissemination.

Salmi LR, Gana S, Mouillet E (2001) Publication pattern of medical theses, France, 1993-98." Med Educ 35 (1): 18-21.

Schattner P, Klein B, Piterman L, Sturmberg J, McCall L (2007) Impact of master of family medicine degree by distance learning on general practitioners' career options. Med Teach 29 (4): e85-92. doi:10.1080/01421590701287905.

Shuval K, Harker K, Roudsari B, et al (2011) Is qualitative research second class science? A quantitative longitudinal examination of qualitative research in medical journals. Plos One 6 (2) e16937. doi:10.1371/journal.pone.0016937

Stern J, Simes R (1997) Publication bias: evidence of delayed publication in a cohort study of clinical research projects. BMJ 39: 1-16. 
Tobar F,Romano Yalour M (2002) Las tesis en las maestrías de salud pública en Argentina.

Accessed 3 October 2013. Available at:

www.federicotobar.com.ar/nf_pdf3/Las_tesis\%20_salud.pdf

Universitat Pompeu Fabra and Universitat Autònoma de Barcelona (2012) Plan de estudios del master oficial en salud pública. Accessed 23 September 2013. Available at:

http://www.upf.edu/postgraubiomed/es/salut/presentacio/

Viana MC, Gruber MJ, Shahly V, et al (2013) Family burden related to mental and physical disorders in the world: results from the WHO World Mental Health (WMH) Surveys. Rev Bras Psiquiatr 35 (2): 115-25. doi:10.1590/1516-4446-2012-0919.

World Health Organization (2006) World Health Report 2006: working together for health. Accessed 23 September 2013. Available at: www.who.int/whr/2006/

Younes R, Deheinzelin D, Birolini D (2005) Graduate education at the faculty of medicine of the University of São Paulo: quo vadis? Clinics 60 (1): 6-8. 
Table 1: Sociodemographic and academic characteristics of students in the Masters program in Public Health (MPH), 2006-2010 ( $n=162)$.

\begin{tabular}{|c|c|c|}
\hline & \multicolumn{2}{|c|}{ Total } \\
\hline & $\mathbf{N}$ & $\%$ \\
\hline \multicolumn{3}{|l|}{ Sociodemographic characteristics } \\
\hline Sex (Women) & 123 & 75.9 \\
\hline \multicolumn{3}{|l|}{ Age group } \\
\hline$<29$ years & 92 & 56.8 \\
\hline$\geq 29$ years & 70 & 43.2 \\
\hline International Student (yes) & 68 & 42.0 \\
\hline Scholarship (yes) & 83 & 51.2 \\
\hline \multicolumn{3}{|l|}{ Academic characteristics } \\
\hline \multicolumn{3}{|l|}{ Undergraduate Studies } \\
\hline Health Sciences & 108 & 66.7 \\
\hline Other Sciences & 54 & 33.3 \\
\hline \multicolumn{3}{|l|}{ MPH Specialty } \\
\hline Research in Public Health & 68 & 42.0 \\
\hline Community Health & 49 & 30.2 \\
\hline Preventive Medicine & 37 & 22.8 \\
\hline Environmental Health & 8 & 4.9 \\
\hline Physicians in Public Health and Prev. Med. Specialty (yes) & 29 & 17.9 \\
\hline MPH completed on time (yes) & 141 & 87.0 \\
\hline Enrolled in a doctoral program after MPH (yes) & 84 & 51.9 \\
\hline \multicolumn{3}{|l|}{ Thesis characteristics } \\
\hline Research Methodology (Quantitative) & 150 & 92.6 \\
\hline \multicolumn{3}{|l|}{ Topic Area } \\
\hline Research in Health Services & 45 & 27.8 \\
\hline Health Promotion and Preventive Medicine & 31 & 19.1 \\
\hline Social Epidemiology & 26 & 16.0 \\
\hline Health Outcomes & 16 & 9.9 \\
\hline Environmental Health & 14 & 8.6 \\
\hline Occupational Health & 9 & 5.6 \\
\hline Other studies of pathologies & 21 & 13.0 \\
\hline \multicolumn{3}{|l|}{ Host Institution } \\
\hline Research Center & 69 & 42.6 \\
\hline Public Health Public Institution & 56 & 34.6 \\
\hline Health Service & 37 & 22.8 \\
\hline Thesis qualification $(\leq 7)$ & 44 & 27.2 \\
\hline \multicolumn{3}{|l|}{ Situation at the time of the survey } \\
\hline \multicolumn{3}{|l|}{ Employment status $^{1}$} \\
\hline Employed & 155 & 97.5 \\
\hline Unemployed & 4 & 2.5 \\
\hline \multicolumn{3}{|l|}{ Present Job } \\
\hline Research in Public Health/Epidemiology & 60 & 38.7 \\
\hline Research in other field & 22 & 14.2 \\
\hline Superior technician in Public Health & 14 & 9.0 \\
\hline Other jobs in Public Health & 32 & 20.6 \\
\hline Other jobs not related to Public Health & 27 & 17.4 \\
\hline \multicolumn{3}{|c|}{$\begin{array}{l}\text { Agreement with the statement "the MPH improved my professional status } \\
\text { and/or progress in my career" }\end{array}$} \\
\hline Disagree or slightly agree & 30 & 18.5 \\
\hline Quite or strongly agree & 132 & 81.5 \\
\hline
\end{tabular}

${ }^{1} 3$ missing values. These values do not count toward the total percentages. 
Table 2: Distribution of theses publication rates according to students' sociodemographic and academic characteristics and thesis characteristics. Masters in Public Health (MPH) students, 2006-2010 (n=162)

\begin{tabular}{|c|c|c|c|c|}
\hline & \multicolumn{2}{|c|}{ Published Theses } & \multirow{2}{*}{$\begin{array}{c}\text { Total Theses } \\
\text { N }\end{array}$} & \multirow{2}{*}{$p$-value } \\
\hline & $N$ & $\%$ & & \\
\hline \multicolumn{5}{|l|}{ Sociodemographic characteristics } \\
\hline Sex & & & & 0.013 \\
\hline Men & 17 & 43.6 & 39 & \\
\hline Women & 81 & 65.9 & 123 & \\
\hline Age group & & & & 0.040 \\
\hline$<29$ years old & 62 & 67.4 & 92 & \\
\hline$\geq 29$ & 36 & 51.4 & 70 & \\
\hline Scholarship & & & & 0.302 \\
\hline Yes & 47 & 56.6 & 83 & \\
\hline No & 51 & 64.6 & 79 & \\
\hline \multicolumn{5}{|l|}{ Academic characteristics } \\
\hline Undergraduate Studies & & & & 0.012 \\
\hline Health Sciences & 58 & 53.7 & 108 & \\
\hline Other Sciences & 40 & 74.1 & 54 & \\
\hline MPH Specialty & & & & 0.207 \\
\hline Research in Public Health & 46 & 67.6 & 68 & \\
\hline Community Health & 28 & 57.1 & 49 & \\
\hline Preventive Medicine & 18 & 48.6 & 37 & \\
\hline Environmental Health & 6 & 75.0 & 8 & \\
\hline Physicians in the Public Health and Prev. Me & d. Spe & & & 0.286 \\
\hline Yes & 15 & 51.7 & 29 & \\
\hline No & 83 & 62.4 & 133 & \\
\hline MPH completed on time & & & & 0.006 \\
\hline 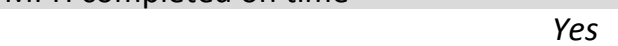 & 91 & 64.5 & 141 & \\
\hline No & 7 & 33.3 & 21 & \\
\hline Enrolled a doctoral program after $\mathrm{MPH}$ & & & & 0.003 \\
\hline Yes & 60 & 71.4 & 84 & \\
\hline No & 38 & 48.7 & 78 & \\
\hline \multicolumn{5}{|l|}{ Thesis characteristics } \\
\hline Research Methodology & & & & 0.166 \\
\hline Quantitative & 93 & 62.0 & 150 & \\
\hline Qualitative & 5 & 41.7 & 12 & \\
\hline Topic Area & & & & 0.040 \\
\hline Research in Health Services & 23 & 51.1 & 45 & \\
\hline Health Promotion and Prev. Med. & 15 & 48.4 & 31 & \\
\hline Social Epidemiology & 20 & 76.9 & 26 & \\
\hline Health Outcomes & 12 & 75.0 & 16 & \\
\hline Environmental Health & 12 & 85.7 & 14 & \\
\hline Occupational Health & 6 & 66.7 & 9 & \\
\hline Other studies of pathologies & 10 & 47.6 & 21 & \\
\hline Thesis host institution & & & & 0.221 \\
\hline Research Center & 47 & 68.1 & 69 & \\
\hline PH Public Institution & 30 & 53.6 & 56 & \\
\hline Health Service & 21 & 56.8 & 37 & \\
\hline Thesis qualification & & & & 0.002 \\
\hline$\leq 7$ & 18 & 40.9 & 44 & \\
\hline$>7$ & 80 & 67.8 & 118 & \\
\hline \multicolumn{5}{|l|}{ Situation at the time of the survey } \\
\hline Present Job & & & & 0.037 \\
\hline Research in Public Health/Epidemiology & 43 & 71.7 & 60 & \\
\hline Research in other field & 14 & 63.6 & 22 & \\
\hline Superior technician in Public Health & 9 & 64.3 & 14 & \\
\hline Other jobs in Public Health & 17 & 53.1 & 32 & \\
\hline Other jobs not related to Public Health & 10 & 37.0 & 27 & \\
\hline $\begin{array}{l}\text { Agreement with the statement "the } \mathrm{MPH} \text { w } \\
\text { in my professional status and/or progress in }\end{array}$ & $\begin{array}{l}\text { Is an i } \\
\text { my ca }\end{array}$ & vement & & 0.033 \\
\hline Disagree or slightly agree & 13 & 43.3 & 30 & \\
\hline Quite or strongly agree & 85 & 64.4 & 132 & \\
\hline
\end{tabular}

p values in bold italics are statistically significant $(p<0.05)$ 
Table 3: Factors associated with publishing the results of the thesis. Masters in Public Health students, 2006-2010 (n=162).

\begin{tabular}{|c|c|c|c|c|}
\hline & $\begin{array}{l}\text { Crude } \\
\text { RR }\end{array}$ & $95 \% \mathrm{Cl}$ & $\begin{array}{l}\text { Adjusted } \\
\text { RR }\end{array}$ & $95 \% \mathrm{Cl}$ \\
\hline \multicolumn{5}{|l|}{ Sociodemographic characteristics } \\
\hline \multicolumn{5}{|l|}{ Sex } \\
\hline Men & 1 & & 1 & \\
\hline Women & 1.51 & $1.03-2.21$ & 1.41 & $1.01-1.98$ \\
\hline \multicolumn{5}{|l|}{ Age group } \\
\hline$<29$ years & 1.31 & $1.00-1.72$ & & \\
\hline$\geq 29$ years & 1 & & & \\
\hline \multicolumn{5}{|l|}{ Academic characteristics } \\
\hline \multicolumn{5}{|l|}{ Undergraduate Studies } \\
\hline Health Sciences & 1 & & 1 & \\
\hline Other Sciences & 1.38 & $1.09-1.75$ & 1.40 & $1.11-1.74$ \\
\hline \multicolumn{5}{|l|}{ MPH completed on time } \\
\hline Yes & 1.94 & $1.04-3.60$ & 2.10 & $1.20-3.68$ \\
\hline No & 1 & & 1 & \\
\hline \multicolumn{5}{|l|}{ Enrolled a doctoral program after MPH } \\
\hline Yes & 1.47 & $1.12-1.91$ & 1.44 & $1.13-1.84$ \\
\hline No & 1 & & 1 & \\
\hline \multicolumn{5}{|l|}{ Thesis characteristics } \\
\hline \multicolumn{5}{|l|}{ Topic Area } \\
\hline Research in Health Services & 1.07 & $0.63-1.83$ & & \\
\hline Health Promotion and Prev. Med. & 1.02 & $0.57-1.81$ & & \\
\hline Social Epidemiology & 1.61 & $0.98-2.66$ & & \\
\hline Health Outcomes & 1.57 & $0.93-2.68$ & & \\
\hline Environmental Health & 1.80 & $1.09-2.96$ & & \\
\hline Occupational Health & 1.40 & $0.73-2.67$ & & \\
\hline Other studies of pathologies & 1 & & & \\
\hline \multicolumn{5}{|l|}{ Thesis qualification } \\
\hline$\leq 7$ & 1 & & 1 & \\
\hline$>7$ & 1.66 & $1.14-2.42$ & 1.61 & $1.12-2.32$ \\
\hline \multicolumn{5}{|l|}{ Present Job } \\
\hline Research in Public Health/Epidemiology & 1.94 & $1.15-3.25$ & & \\
\hline Research in other field & 1.72 & $0.96-3.09$ & & \\
\hline Superior technician in Public Health & 1.74 & $0.92-3.26$ & & \\
\hline Other jobs in Public Health & 1.43 & $0.79-2.59$ & & \\
\hline Other jobs not related to Public Health & 1 & & & \\
\hline \multicolumn{5}{|c|}{$\begin{array}{l}\text { Agreement with the statement "the MPH improved } \\
\text { my professional status and/or progress in my career" }\end{array}$} \\
\hline Disagree or slightly agree & 1 & & & \\
\hline Quite or strongly agree & 1.49 & $0.97-2.28$ & & \\
\hline
\end{tabular}


Figure 1: Bibliometric indicators for published thesis results $(n=87)$.

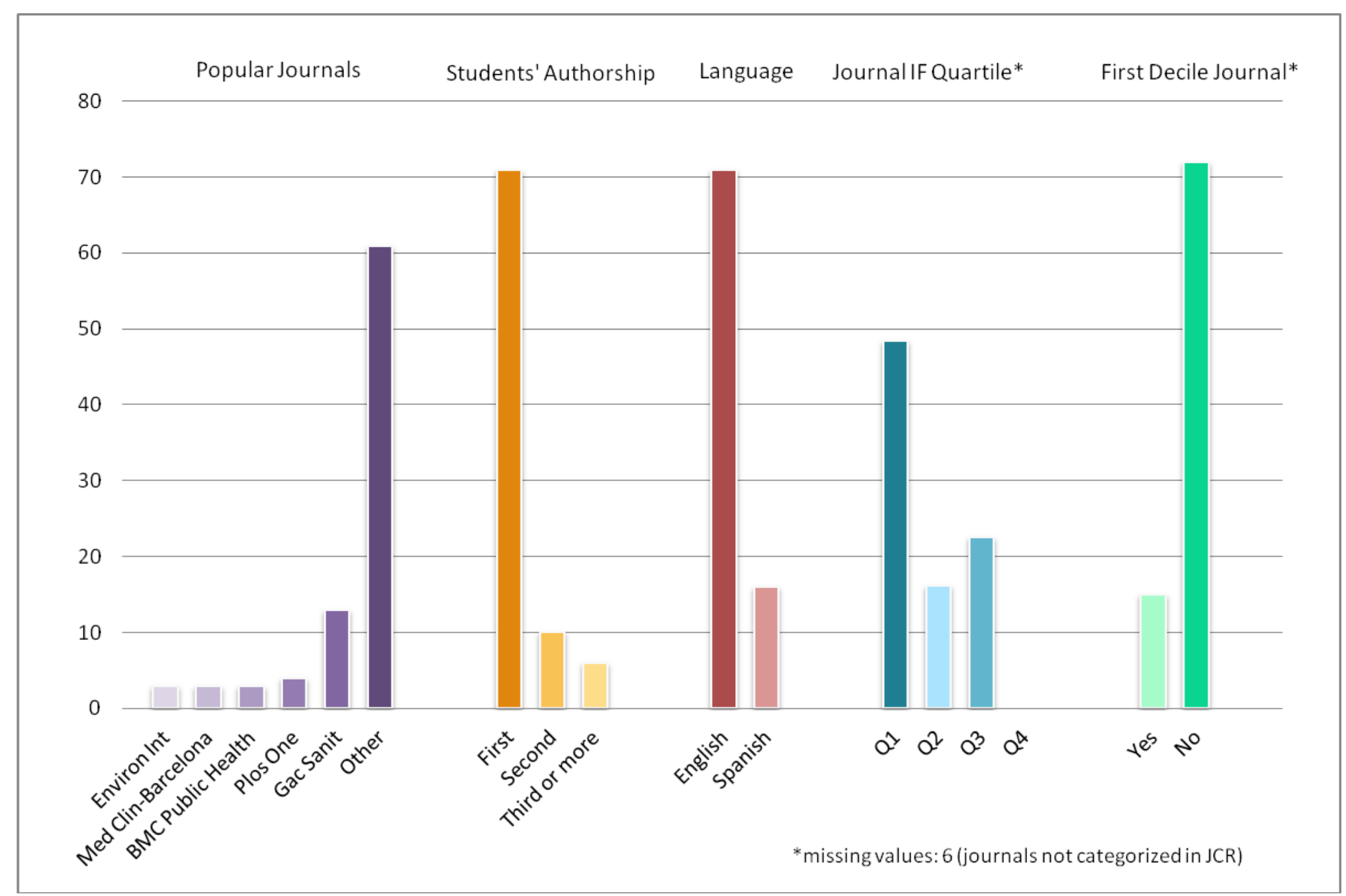

